\title{
A Conceptual Framework for Urban Commoning in Shared Residential Landscapes in the UK
}

\author{
Aimee Felstead *(D), Kevin Thwaites and James Simpson (1) \\ Department of Landscape Architecture, University of Sheffield, Sheffield S10 2TN, UK; \\ k.thwaites@sheffield.ac.uk (K.T.); j.c.simpson@sheffield.ac.uk (J.S.) \\ * Correspondence: alfelstead2@sheffield.ac.uk
}

Received: 12 July 2019; Accepted: 29 October 2019; Published: 3 November 2019

check for updates

\begin{abstract}
This paper uses ideas central to the notion of urban commoning to develop a conceptual framework that can be used to inform the design and management of shared residential landscapes in the UK. Shared residential landscapes provide an important backdrop for everyday social interaction, chance encounters and mutual understanding. A recent revival of the commons concept within the urban context has brought forth new ideas for the design and long-term management of shared urban resources through participation and collective action. However, despite the potential benefits of urban commons for improved quality of urban living, there remains a disconnect between commons and spatial theory, obstructing effective application. Of particular significance are the role of physical space and the design professions in enabling or hindering the collective practice of urban commoning. To address this, this paper reviews the evolution of the commons, the implications for applying them to the urban context, and spatial theories in developing a conceptual framework for their application within the UK residential sector. Finally, the example of cohousing in the UK is drawn upon as an illustration of the urban commons framework. The framework creates a foundation for further research on the design and long-term management of shared residential landscapes as urban commons to benefit the everyday social lives of residential communities.
\end{abstract}

Keywords: urban commons; residential landscapes; spatial theory; cohousing; governance; shared resources; territory

\section{Introduction}

In recent years, a significant amount of attention has been focused on the sustainable development of urban landscapes [1-4], with notable focus on residential settings [5,6]. This coincides with a growing understanding of the opportunities offered by urban commoning [7-10], an emerging concept describing the collective governance of shared resources in the city by communities [11,12]. The term 'urban commons' has gained momentum in recent years as part of a wider 'new commons movement'. This has seen the reinterpretation and broader application of the traditional commons concept within contemporary contexts $[13,14]$. However, the novel and diverse use of the word 'commons' presents its own challenges, in particular, in that it has become "a term frequently applied yet rarely defined" [13] (p. 3). Despite the term resonating with an emerging sharing culture within cities [15] and participatory approaches to designing the city [16], the term urban commons remains ambiguous and difficult to pin down. In particular, conceptualising city spaces as urban commons, highlights a need for a spatial understanding $[17,18]$ and a stronger connection between the concept and urban spatial theory. The current paper argues that there is potential to align commons thinking with urban spatial theory in order to strengthen its applicability. This will focus on the context of shared residential landscapes, where the commons concept offers potential to encourage a more socially sustainable and bottom-up approach to participatory placemaking. While new community-led practices are emerging and calling 
for greater collaboration with urban professionals, there remains a gap in the theory to underpin how the ideas of urban commons relates to the residential context. In response, this paper highlights the need for a place-based understanding of the urban commons concept to enable the sustainable design and management of shared residential landscapes as urban commons.

In pursuit of bridging this gap, the current paper will focus on addressing the need for a spatial understanding of commons in the context of urban residential landscapes by developing a new conceptual framework for urban commons that strengthens the connection between the emerging concept and spatial theory. To achieve this, a review approach will draw upon and organise existing commons and urban spatial concepts to build a preliminary conceptual framework within the context of recent UK cohousing research. The purpose of this preliminary conceptual framework is to lay the theoretical groundwork for future empirical research on urban commons specific to residential landscapes and substantiate more broadly the spatial theory surrounding urban commons. In the process of bridging spatial and urban design theory with urban commons, attention is also brought to the role of the design professions and how professional input can be accommodated within the community-led process of urban commoning.

\section{Background and Context: Shared Residential Landscapes and Urban Commons}

In 2017, the UK Government set out plans to build 300,000 new homes a year in England in an attempt to tackle ongoing issues around the affordability and availability of housing [19] (s.5.3). The concern from a social sustainability perspective is how, in the long-term, these new homes will contribute to the everyday social lives of the communities that will live there. In particular, how the spaces between buildings can provide an opportunity for social interaction and engagement.

Shared residential landscapes are socially valuable spaces that form the backdrop to everyday routines, social encounters and community identity [20]. The characteristics and qualities of these spaces, shaped by their design and maintenance over time, have a significant influence on the social aspects of a neighbourhood [21-23]. Aligned with this is the understanding that people's direct interaction with the surrounding environment can provide opportunities for expressing identity, receiving recognition from others and developing a greater sense of belonging [24]. Resident control over shared outdoor spaces also allows potential for residents to shape their common surroundings in a way that is beneficial to them, providing agency over the way they live $[25,26]$ and increasing opportunities for social interaction [27].

A way of encouraging greater potential for communities to have a decision-making role within the make-up of their residential environment can be seen within the community-led housing sector $[26,28,29]$. Even though profession-led top-down approaches remain the predominant model for new housing development in the UK, community-led housing is growing in popularity, something that has been recognised in the UK government's 2018 announcement of the $£ 163$ million Community Housing Fund [30]. Community-led housing challenges some of the limitations within contemporary housing development by generating a new bottom-up approach that shifts residents' roles from end users to engaged participants in aspects including anything from site acquisition to management.

Cohousing is a particular model of community-led housing characterised by its combination of individual private dwellings with shared facilities and resident-led decision making during the design, development and occupation phases [31,32]. Examples of cohousing in the UK are located in both urban and rural contexts and built with a range of densities and layouts [33]. Although cohousing developments are spatially diverse, they are based upon similar design and organisational principles that promote collaborative ways of living [6]. Subsequently, residents have high levels of involvement in the maintenance and management of communal spaces, organisation of social activities and the decision and rule-making process of the community [6,34]. A review of recent research suggests multiple benefits associated with cohousing, including decreased energy use, affordable living costs, enhanced connection to place, improved self-awareness, strong community relations, mutual support 
and knowledge sharing [34-38]. Cohousing, therefore, provides a useful illustration for the potential of collective participation in residential placemaking.

Notable within the increasingly popular community-led housing sector, and resident participation in shared residential landscapes more generally, is the emerging concept of urban commons. While the evolving meaning of the term commons has created a usefully flexible concept applicable to various resources in different contexts and at multiple scales, it remains conceptually challenging in its vagueness $[13,17]$. In applying the commons concept within the urban context, the theoretical implications are yet to be fully explored. Furthermore, a polarisation between top-down and bottom-up approaches to urban development in the UK presents additional challenges of integrating commons as a bottom-up approach within the top-down guidelines and practices of urban professions $[34,39]$. Therefore, even though the broadening of the commons concept to include shared urban resources has stimulated a reconceptualisation of collective governance in cities generally, challenges remain surrounding clarity in its definition, understanding the spatial implications, and the role of urban professionals in its implementation. These limitations in understanding the urban commons create challenges to appropriately applying the theory in urban residential contexts.

To address these challenges, this paper aims to develop a new conceptual framework for urban commons that strengthens the connection between the emerging concept and spatial theory. This is realised within the following objectives and methodological steps for a literature review of existing commons theory, urban spatial theory and UK cohousing literature (as illustrated in Figure 1). Firstly, (1) a review of recognised commons literature is undertaken to highlight the defining components of commons in both traditional and urban settings. Secondly, the contemporary urban commons literature is reviewed to identify the implications arising from the application of the commons idea within urban settings. Thirdly, (3) relevant concepts within urban spatial theory are drawn upon to explain and underpin the implications identified within the urban commons literature. Fourthly, (4) a preliminary conceptual framework is outlined to draw together the key concepts that connect urban commons with urban spatial theory. Finally, (5) the concepts are pre-emptively illustrated within the context of residential landscapes using examples from recent cohousing research in the UK.

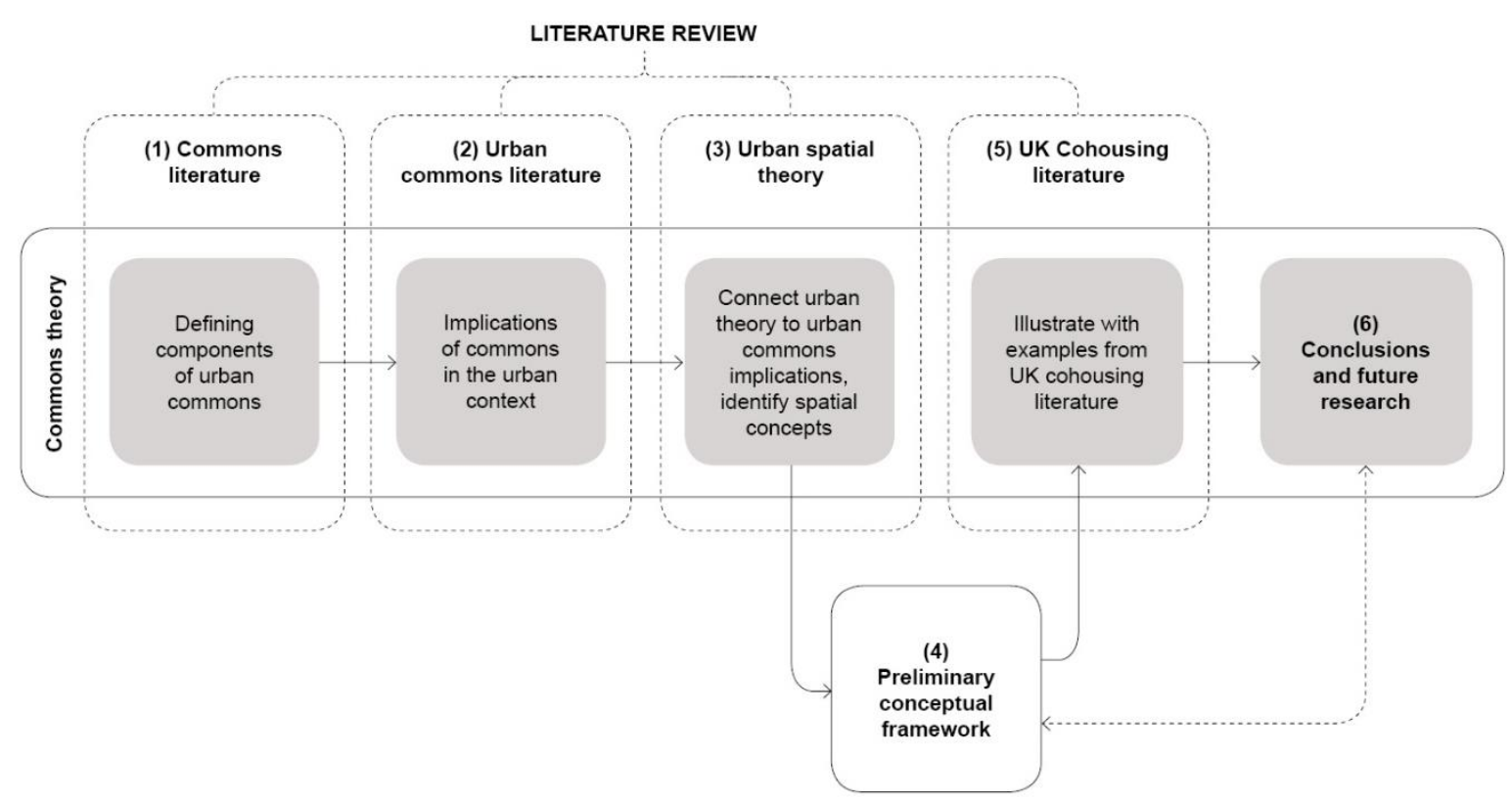

Figure 1. Diagram illustrating the methodological flow for developing and illustrating the conceptual framework from the literature review. 


\section{Urban Commons: A Review}

The urban commons is a concept evolving from the economics theory of common-pool resources [12] and subsequently applied to the context of the city [7-10,40]. This paper draws on the idea of urban commons to conceptualise resident participation in the governance of shared residential landscapes. This section reviews the emerging concept of urban commons and explores its varying interpretations to develop a common definition that can be more readily applied within urban design professions. In doing so, the review highlights a number of implications, as a result of applying commons theory within the urban context, which form the basis for the conceptual framework.

In the UK, a commons is traditionally associated with historical areas of uncultivated land allocated with shared rights such as grazing and foraging. This was the image that Hardin [41] had in mind when he argued that natural resources, such as an open access field shared by unrestricted numbers of people, are inevitably exploited by those working in their own self-interest, leading to the resource's eventual demise. He called this the 'tragedy of the commons', a phrase that formed the argument upon which commons were stripped of their common rights and transformed into private or public access land through successive acts of enclosure. Although the tragedy of the commons is a useful analogy to describe the exploitation of natural resources witnessed today on a global scale, the idea that all commons were destined for self-destruction was successfully challenged by Elinor Ostrom [12]. She highlights that the open access and vulnerable resources that Hardin based his argument on are defined by two key characteristics: subtractable- the ability for a resource to be depleted by consumption - and nonexcludable—difficulty in restricting access to a resource. Ostrom subsequently used the term common-pool resources to describe resources particularly vulnerable to practices of over-use and exploitation. Though common-pool resources reinforce Hardin's idea of a commons defined as a type of shared natural resource, Ostrom's extensive game theory modelling and empirical observations of commons revealed important yet previously overlooked social dimensions. Ostrom identified cases of common-pool resources around the world that demonstrated enduring and self-sustaining qualities. In endeavouring to identify the characteristics that enabled sustainable resource management of common-pool resources, Ostrom discovered that these shared resources were restricted to a defined group of people who actively participated in outlining their own rules, boundaries and agreements, enforcing sanctions and resolving conflicts. The findings, summarised in the design principles for long-enduring common-pool resource institutions [12] (p. 90), outline the need for resource users to have a participatory role in the governance of a shared resource. In doing so, Ostrom's theory contributes essential social and organisational dimensions in defining successful commons, in particular, the need for a defined community of end users and their ability to collectively participate in the governance of a shared resource.

Thus, research on common-pool resources conjures additional meaning for the commons. The term simultaneously describes a shared resource, a social process, collective activity and rules of governance. In searching for a definition of the commons, three essential components are identified from the theory of common-pool resources: 1) a shared resource, 2) a community of resource users and 3) collective governance. Specifically, the relationship between these components is key to defining what make a commons. As Harvey later describes, "The common is not to be construed, therefore, as a particular kind of thing, asset or even social process, but as an unstable and malleable social relation between a particular self-defined social group and those aspects of its actually existing or yet-to-be-created social and/or physical environment deemed crucial to its life and livelihood" [40] (p. 73). Harvey reinforces the idea that although a physical shared resource is an essential component of a commons, without its integral social relationship with a defined community of end users and their collective participation in its governance, the shared resource cannot be sustained as a commons. Maintaining a bottom-up approach in the governance of commons is, therefore, a key aspect to their existence, and without the latter aspect of collective autonomous governance, the resource becomes subject to potential tragedies $[11,12,40]$.

Ostrom's early work, based largely in the rural context, validated the commons idea as a sustainable governance approach and established the theoretical stronghold of commons within the 
discipline of economics. In doing so, her work paved the way to expand the application of the commons concept and its theory to a range of new resources, both physical and intangible, including knowledge [42], the Internet [43], culture [10], and the city [9,17,40,44]. Ostrom's theory and rules for common-pool resources were developed in primarily localised rural contexts, and so the dense human-made environments of the city brought new socio-political contexts for commons to exist within. Hess notes the reinterpretation of commons within a 'new commons movement', denoting a societal desire to take back control of public resources in response to "increasing commodification, privatisation, and corporatisation, untamed globalisation and unresponsive government[s]" [13] (p. 3). The movement suggests an expansion of the idea of commons as a form of sustainable and collective resource management to include broader political debates on social justice and promote inclusive open access within the city's spaces. This evolving use of the term commons within the urban context is underpinned by Lefebvre's idea of 'The Right to the City' [45] and later reinterpreted by David Harvey [40]. Harvey emphasises that 'the right to the city' encapsulates not only an inclusive right of access to the cities spatial resources but importantly, includes a right to remake those spaces to suit the needs and desires of those that live there. The argument is formed on an integral relationship between people and their environment. Harvey describes this "as a right to change ourselves by changing the city" [16] (p. 23), echoing the words of Berleant, "what we do in environment, we do to ourselves" [46] (p. 121) and Alexander et al., "that towns and buildings will not be able to become alive, unless they are made by all the people in society" [47] (p. $\mathrm{x}$ ). Harvey, Berleant and Alexander's words acknowledge the agency afforded to those who are given the opportunity to change their surroundings in deciding how they wish to live and the places they live in.

Harvey recognises an agency over one's environment as being an explicit right. In doing so, he also recognises that within the compact environment of the city, there is a collective right whereby an individual's actions in remaking the environment should consider the impacts upon others. This raises some interesting tensions between the idea of inclusion and exclusion within urban commons. Where Ostrom's common-pool resources are formed around defined communities and enclosed shared resources protected from outside exploitation, Harvey presents a more public vision for urban commons that have inclusive access, collective participation and a shared understanding on a wider scale. Within the urban context, the tensions between insider and outsider, inclusion and exclusion, become all the more apparent due to increased demand for resources and contestation for space. In some cases, enclosed types of urban commons that restrict access or use within urban public spaces, can exhibit characteristics similar to privately owned public spaces, whereby trade-offs are imposed on public use and access [44,48]. Clarifying this apparent conflict between urban commons and public space, Harvey explains: "There is an important distinction here between public spaces and public goods, on the one hand, and the commons on the other... While these public spaces and public goods contribute mightily to the qualities of the commons, it takes political action on the part of citizens and the people to appropriate them or to make them so" [40] (p. 72). In searching for a definition for urban commons and untangling their relation to public space, Harvey highlights that public space is not to be automatically equated with urban commons. Instead, he acknowledges that public space can become an urban commons if a collective, and often political, movement takes ownerships of them. This collective movement can often represent the initial stage in instigating collective governance of a shared resource. It is important to recognise that there is often an inherent tension within urban commons, between public and private, or inclusion and exclusion, and to be aware of who the urban commons is for.

The definition of an urban commons incorporates new ideas of inclusivity beyond the smaller scale, localised communities of traditional commons. As such, they become encapsulated within a political and activist context of 'the right to the city' that calls for equal recognition of all citizens and their influence on one another at the city scale. Despite the addition of broader political debates and social justice discourses, the urban commons retain a relationship between the three essential components previously identified within the definition of a commons. In the urban context, these components can be recognised as 1) the city and its urban spaces as a shared resource, 2) the city's residents as a community of resource users and 3) residents' participation in the city, through political movements or 
resource management, as a form of collective governance. While the defining components remain broadly the same in the urban context, the unique characteristics of the urban in comparison to the rural suggest that urban commons have distinct differences from their traditional counterparts. In reviewing the evolution of the commons and the 'new commons movement', several differences and implications for the urban common are revealed. Firstly, the differing social dynamics and characteristics that exist within urban settings call for urban commons to form within dynamic, temporal and disconnected populations $[49,50]$. Secondly, in highlighting the relationship between people and their environment at the city scale, a spatial dimension becomes more apparent within the density of the city, something that has thus far been underexplored in the urban commons literature [18]. Thirdly, the literature suggests that urban commons play a potential role in the production of urban place or city-making $[17,40]$. Finally, urban commons are implemented within the institutional, legal, and planning frameworks of the city, and thus, commoning groups often require partnerships with various professions, organisations or institutions to negotiate these frameworks [17]. Therefore, this paper echoes the call for a conceptual framework for the commons that deals with the urban, in particular, a spatial and place-based understanding to enable the design and management of shared residential landscapes as urban commons.

\section{Developing an Urban Commons Framework}

To provide a new urban, spatial and place perspective on the urban commons concept, this paper frames the concept of urban commons around the four implications identified. These include 1) the need for a relatively disconnected and dynamic urban population to work toward a common interest, 2) to understand the spatial manifestations of urban spaces as shared resources, 3) the process of commoning as a potential production of place and 4) the need for commoning communities to work with external professionals and within institutional frameworks. To develop an urban perspective on these implications, the following discussion spatialises commons theory by drawing upon the ideas of informal urbanism, territory, placekeeping and partnerships.

\subsection{Working Together as Strangers}

To explore the spatial implications of urban commons, the framework begins by looking at what drives their initial formation. Ostrom marks the success of commoning as relying on communities that "share a past, and expect to share a future" [12] (p. 88). Therefore, the relatively close-knit and stable characteristics of rural communities compel individuals to work together in anticipation of long-term mutual benefit and trust. In contrast, the city is characterised by a dense saturation of people living as relative strangers $[50,51]$. Urban commons emerge without the default commonality and established trust of rural communities-a prerequisite to commons formation. Examples of urban commons in recent research demonstrate emergence in response to privatisation and limitations on urban life [52], tenants in danger of eviction [50,53], campaigns against demolition and in support of neighbourhood revitalisation [54] and movement against climate change [55]. These examples suggest that instead, urban commons form in response to a threat, need, desire or ideology. Huron [50] highlights in her research that within the city, there is a dialectic relationship between commons and community formation that differentiate urban commons from their rural counterparts. Community is not a prerequisite to urban commons formation, but rather a simultaneous process of commoning and community formation triggered by a particular urban condition that drives a common mindset.

The organic and emergent nature of commons formation, centred around a common mindset, can be further explained through the idea of a sharing culture [15] and the understanding of the urban context through complex-adaptive assemblage theory [56]. Sharing culture is defined as a shared goal to "co-produce, manage, and shared resources ... based on solidarity and reciprocity rather than economic profit" and "relates to social networks that grow informally within a region between diverse stakeholders" [15] (p. 430). Katrini highlights that a sharing culture is triggered in reaction to wider contextual changes, such as a withdrawal of public services, and makes use of and adapts available resources and materials. The city, 
therefore, provides both a context and a driver for sharing practices, produced from ongoing changes in the relationship between multiple urban influences. Complex-adaptive assemblage theory provides a useful way of conceptualising informal urbanism, considering the city as a larger 'whole' assembled from underlying connections between multiple components that exist in a constant state of change or 'becoming' [56]. Put more simply, the city is a collection of connected elements, such as "buildings, houses, shops, signs, cops, shoppers, cars, hawkers, rules, sidewalks, goods, trolleys, etc. all come together to become the street ... " [56] (p. 353). Within the assemblage of elements, of particular importance are the connections between them, "the relations of buildings to sidewalk to roadway; the flows of traffic, people and goods; the interconnections of public to private space, and of the street to the city." [56] (p. 353). The assemblage itself, its components and relationships are dynamic and ever-changing and therefore, the interactions and outcomes unpredictable. Therefore, complex adaptive assemblage thinking helps explore the dynamics of interactions between the many components that make up the city and the emergent nature of informal urban phenomenon. It describes a relationship between parts that are at once independent and unpredictable, yet interdependent, so when a change occurs in the assemblage, all the other parts adapt in response. Practices of sharing culture emerge as a form of adaption in response to other changes within the assemblage of the city and exist within reactive cycles of emergence, stabilisation, release and re-organisation [56]. The common mindset can be understood as a form of self-organised and informal adaption in response to shifts within the urban assemblage, such as the components of housing affordability, vacant land, and privatisation.

So what does this mean for the application of urban commons in the residential context? Significantly, urban commons are not easily predetermined, or in other words, they cannot be readily designed. This is problematic for urban professionals, such as landscape architects, seeking to implement such ideas within residential landscapes through traditional top-down means. In understanding a common mindset as an emergent phenomenon, urban professionals play an important role in recognising and validating the ideology or goals of a group and putting in place available services and frameworks that enable those goals to be achieved. Thus, they aid in reducing friction along the routes towards establishing an urban commons by identifying the barriers and understanding what can enable or support such practices. Overall, what this section of the framework emphasises is firstly the need to recognise and understand the common goal underlying urban commons formation and secondly the supportive, but not determinate, role urban professionals play in it. The ways in which this might happen are explored in the following three sections of the framework.

\subsection{A Spatial Understanding of Urban Commons}

Urban contexts bring together both social and spatial considerations. The previous section outlines the implications of some of the social characteristics of the urban, living amongst strangers. The current section will now explore the spatial implications. The 'urban' describes a size, scale, density, diversity and temporality [57], all of which are descriptors of the city's physical form. Urban commons, by the definition of what is urban, have spatial as well as social implications $[15,40]$. To define what is meant by space, this paper looks toward a multi-faceted understanding outlined by Lefebvre: the abstract mental construction of space, the production of physical space, and the experience of living in and through space [45]. Through this understanding, urban commons are recognised simultaneously as being spatially perceived in the minds of commoners, physically conceived through collective action and experienced through everyday occurrences. Urban commons are at once a product of the city and a producer of urban space, concurrently experienced by commoners [45]. Therefore, the implication for the theory of urban commons is that our understanding is not limited to a spatial form created by collective action nor solely a social organisation produced from a spatial resource; rather they emerge from the reciprocal relationship between both-a socio-spatial manifestation. Such a mindset inherently places significance upon the linkage between such social and spatial considerations, which, when viewed within the context of commons thinking, can be reflected upon in terms of territory. 
Territory is a form of control that explains the relationship between the social and the spatial. In other words, territory describes a spatial extent, the area within a set of physical limits, and a social scope, demarking who is allowed within the space and what norms are expected within it. Yet, territory differs from formal legal ownership and rights in that it portrays a perceived sense of belonging to a space [58]. A territorial awareness, therefore, not only helps to distinguish between what is mine, what is someone else's and what is shared, but also strongly relates to an individual's awareness of self, self-esteem and position within society. In other words, through their collective actions, commoners can manifest their common mindset, rules and norms into something physical, such as the adaption of boundaries, placement of objects and physical occupation of space. In witnessing this physical expression, it allows individuals to become aware of their own mindset and, furthermore, their position within society by recognition of their actions by others. Honneth [59] considers recognition of self-identity and status within a mutually supporting community as essential for human fulfilment. Landscape theory highlights that achieving this human fulfilment for recognition requires it to occur within a spatial context or territory [24].

Territory, as a manifestation of the relationship between people and their environment through its control is, therefore, expressed both spatially through the adaption of boundaries, placement of objects and occupation, and socially through the rules, sanctions and norms applied to those spaces. The idea of territory, while not explicitly mentioned in commons theory, is highly relevant to urban commons and the common mindset, particularly in relation to territories that express a shared sense of belonging. This perceived sense of shared belonging is described within the MYTO territorial framework [60] as 'ours'. Where 'mine' describes an individual's perception of space over which they have sole control—such as a private garden—and 'yours', a space controlled by some other known person—such as a neighbour's wall-'ours' delineates a space controlled by a group of people of which an individual feels they belong-such as a shared entrance to a block of flats or a community allotment. 'Ours', therefore, represents a terrain requiring cooperation, a consciousness of others and a common understanding and, in doing so allows individuals to feel a greater sense of belonging to a group of people and the place in which they live [60]. 'Ours' as a shared territory provides opportunity for the spatial expression of the common mindset, recognition of an individual's position within the community and developing a shared understanding.

The spatial dimension of urban commons as a form of shared territory lies within the understanding of how 'ours' is spatially defined and what types of spatial infrastructure enable a sense of 'ours' to be expressed more readily. Within the residential landscape, proximity of 'ours' to 'mine' may have several advantages in creating a balance between expressing self-identity in 'mine' and overcoming excessive introspection and settling of differences in 'ours' [58]. In placing shared territorial landscapes near the frequently occupied spaces of private dwellings, there is a provision of more frequent opportunities for territorial expression through natural surveillance, defensible space, physical occupation and appropriation. The spatial configuration of the boundaries between 'mine' and 'ours' enable a balance between privacy or maintaining a sense of self-identity, with publicness, sharing and commonality. The spatial characteristics that enable this balance are described by Martin [61] as 'hide and reveal', a phenomenon observed in residential back alleys that enables a porosity between preservation of privacy and opportunities to be more readily situated in open and social spaces. In this respect, Martin's 'hide and reveal' resonates with Appleton's theory of 'prospect and refuge' [62] in highlighting the importance of spatial arrangements that afford simultaneous opportunity for people to feel protected whilst maintaining surveillance.

A similar relationship, thereby, exists between shared spaces as a form of 'ours' and the wider public realm, a larger scale of 'ours'. The thresholds that define the edges of shared territories are important in defining what kind of relationship urban commons have with adjacent territories. Thresholds can be expressed in several ways, including physical boundaries, symbolic representation, the placement of objects [58], physical occupation [63], maintenance, the temporary adaption of space [64], social norms and group membership [12]. The idea of thresholds crops up in several 
ways within the commons literature. Firstly in Hardin's conception of the boundless grazing field in danger of exploitation, and then in Ostrom's first rule for common-pool resources- "clearly defined boundaries" [12] (p. 90), referring both to the individuals with access and the resource itself. These references suggest the need for defined territorial boundaries surrounding spatial shared resources. However, the more recent 'new commons movement' promotes a shift away from processes of enclosure associated with privatisation and commodification and thereby advocates the removal of physical barriers and restrictive thresholds. The balance between openness and enclosure within urban commons is not a straightforward contradiction to solve. Harvey suggests that not all forms of enclosure are negative and can be necessary in the protection of certain types of shared resources in the complex, often competitive and contested nature of the city [40]. It is important to understand the level of inclusion and openness required in relation to different types of urban commons in spatially configuring territorial boundaries. Residential urban commons, in particular, may require territorial thresholds that define space in relation to the specific community of residents, yet enable wider interaction with the broader neighbourhood. Subtle attention to the height, depth, transparency, porosity and flexibility of territorial edges expresses potential balances between complete enclosure from the outside and undefined openness. The adaptability of such edges also enables commoning communities greater temporal control in expressing not only who is allowed access, but also when. The opportunity for the placement of symbolic markers and physical occupation of territorial thresholds is increased where the spatial depth of a threshold is increased. Described as a 'transitional edge' [60], 'soft edge' [22] or a 'margin' [58], the depth of a threshold can provide additional opportunities for resident participation, shared control and social inclusion.

Whilst some of the spatial concepts mentioned here, such as soft edges [22,60] and defensible space [65] are well recognised within the theory of residential urban design, there application to the urban commons concept is less established. Therefore, careful consideration needs to be given to territorial arrangement in relation to urban commons and how territorial thresholds are best expressed to reflect relationships with surrounding urban contexts. The challenge within the application of this idea into the residential context is who is in control of deciding how territory is arranged and defined. Territory is at once related to a very personal expression of belonging, largely out of control of the urban professional. Examples have shown how territory can be very difficult to assert without the presence of some spatial infrastructure or cues to indicate where individual and shared control begins and ends. Therefore, the role of the urban professional is to determine not only the spatial arrangement of territory and thresholds but also to understand what level of intervention is required of them and what understandings are already in place within the common mindset.

\subsection{The Production of Urban Commons as Placemaking}

To date, in its evolving definition, urban commons are considered as both a long-term process of sustaining a shared resource [12] and a short-term goal of reclaiming spaces in the city [50]. Huron, identifies that within the urban context, following successful reclaiming of urban resources, there is a need for that resource to be maintained through long-term governance. The adaption of urban spatial resources through their initial acquisition and longer-term governance to suit the everyday needs of urban residents, therefore, influences the spatial, social, political, cultural and material dimensions of that resource. Place is a word that can be used to describe the coming together of the multiple dimensions associated with urban spatial resources. Dovey [56] highlights that place distinguishes itself from space by describing a measure of intensity, such as vibrancy, activity or other qualitative characteristics that the dimensional measures of space cannot portray. In the case of urban commons, place is a useful term to describe the developing product between an urban spatial resource and the social dimensions of collective governance and the process of commoning. Placemaking describes an approach to delivering places in a way that strengthens the connections between people and place [66] and placekeeping is a term that emphasises the role of long-term and ongoing practices of maintenance, management and governance in the creation of place [67]. Together, placemaking and 
placekeeping describe the process through which urban commons are realised spatially through the everyday activities, perception and participation of end users through collective governance.

The factors that influence placemaking are complex and multiplicious. Franck and Stevens [68] use the term 'loose space' to summarise the characteristics that enable people to appropriate and adapt space to meet their needs and desires. 'Looseness' relies largely upon individual people's belief of what is admissible or allowed a belief in their abilities, skills and recognition of new possibilities. Therefore, loose spaces provide physical opportunities for looseness, people's perceived potential to create place, to be fulfilled. According to Franck and Stevens [68], the characteristics of loose space relate to spatial diversity, physical disorder and affordance. Firstly, greater spatial diversity, the variation in physical form, creates increased possibilities for how that space can be inhabited and adapted and by whom. Secondly, physical disorder relates to a lack of regulation, lower surveillance, visible physical deterioration and ambiguity in the control of space that allows individuals increased freedom to take ownership of space. Lastly, affordance describes the ability for physical features to provide multiples uses, the occupation of space enabled by graduated transitions at thresholds and moveable, flexible and malleable elements. While spatial diversity, physical disorder and affordance hinge on increased flexibility and reduced definition, a lack of spatial elements and too much openness can also restrict opportunities. Dovey describes this as a tension between stable, enclosed territories and the absence of defined territorial boundaries [69]. He describes a tension within place that is constantly shifting with spaces having the potential to accommodate new and unpredictable forms of placemaking that stabilise in time toward enclosed territories until the cycle begins again. The crux of loose space and the encouragement of placemaking through forms of urban commoning centres on the provision of spatial form that can be readily adapted and the relinquishment of some level of control, definition and prescription in favour of flexibility, adaption and the unknown.

\subsection{Partnerships and collaborations}

The urban context creates several challenges for bottom-up movements, such as commons, to take hold, due to the difficulties in navigating its numerous top-down frameworks, such as planning and legal systems [34]. While some urban commoners may utilise knowledge from within their group where they comprise members with professional positions and specialist knowledge, many require support, partnerships, collaborations or consultation with external professions and organisations to negotiate such frameworks. This may be in the form of support, guidance and open-mindedness from housing associations, tenants and residents associations and local councils, or advisory roles and participative approaches from design professions. Within urban commons, there is a shift away from traditional client-professional relationships towards a collaborative or supportive partnership between bottom-up and top-down actors. The placekeeping conceptual framework [70] describes a shift away from a single universal governing body toward a liaison among a variety of stakeholders in the delivery of place. Successful approaches to place governance combine local knowledge, skills, time and resources with external resources, professional expertise and public enablement. Despite these benefits, there continues to be several barriers to community involvement in the design and maintenance of urban residential spaces. A contributing factor to this problem is the polarisation between top-down and bottom-up approaches to design, implementation and management in urban development $[25,71]$. The predominant top-down approach to residential placemaking in the UK today creates barriers to people focused placemaking and a disjointed and uncoordinated approach to its long-term place maintenance and management [70].

A recent political shift toward localism, alongside austerity measures and local authority withdrawal from the public realm in the UK [55] has created regulatory slippages [17] in top-down placemaking provision that community-led approaches have been able to occupy [72]. Research into this phenomenon, described as 'improvised', 'interstitial' and 'makeshift' urbanism (amongst others) [72], demonstrates a number of potential benefits, including improved quality of space [54,73], social interaction and community cohesion [74], and individual wellbeing and expression of 
self-identity [75]. However, such examples also demonstrate significant barriers to bottom-up participation in placemaking within institutional, legal and design frameworks [54], a lack of empowerment to influence external authorities and relations [52], and a limited capacity for resources, skills and time [75,76]. Ostrom's last principle for common-pool resources attempts to address issues of scale and power through the implementation of multiple layers of nested institutional rules [12] that enable both top-down and bottom-up approaches to work together. Thus, the success of urban commons relies on maintaining open communication channels from the bottom to the top to enable a common mindset to extend beyond internal relationships to include external professions, organisations and institutions.

The emergence of commons within the urban context not only calls for collaborations between communities and urban professionals but a new facilitating role to enable such change to happen. This can be explained using Arnstein's ladder of participation [77]. The participative relationship between urban commons communities and professions, organisations and institutions is positioned on the top three rungs of the ladder of participation (citizen control, delegated power, and partnership; see Figure 2). Any position lower down the ladder would hinder the commoners' ability to maintain collective participation in devising, monitoring, sanctioning and resolving their own rules [12], a defining characteristic of a commons. Therefore, the role of the urban professional needs to shift to reflect this new relationship, from client-profession to one of supporter, facilitator and partner. This requires a willingness of urban professions to relinquish some level of control and a preparedness to work with the unknown.

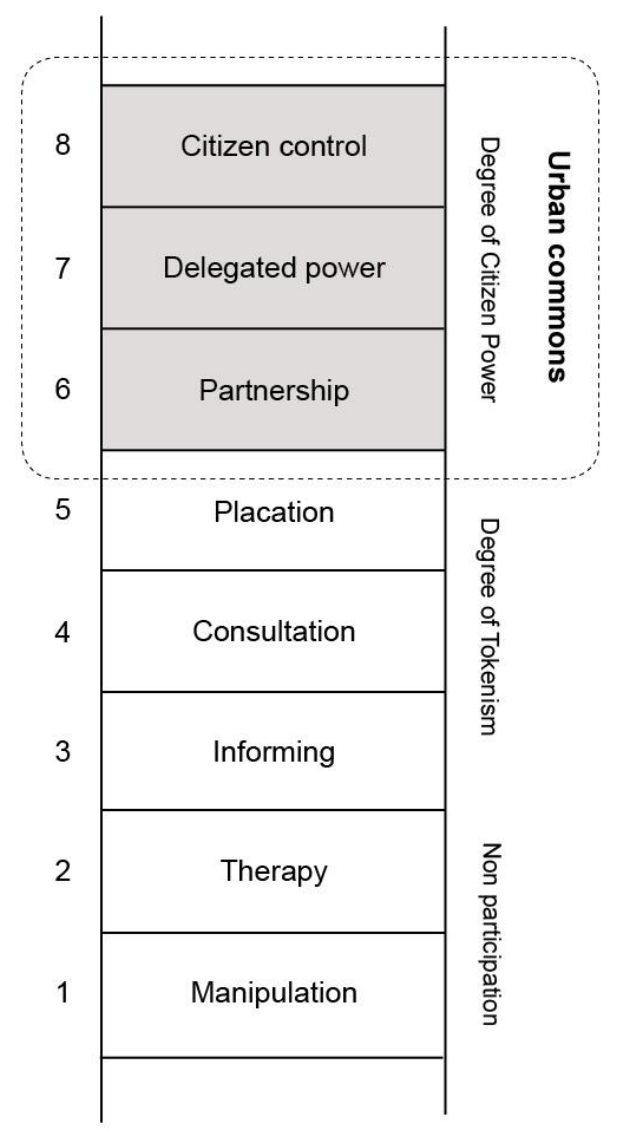

Figure 2. Urban Commons are defined by the collective ability of commoners to participate in its governance, situating them on rungs 6-8 on Arnstein's ladder of participation. Below these rungs, in the zones of 'Tokenism' and 'Non-participation', commoners lack the necessary control to define their own rules, and therefore their status as a commons. Adapted from Arnstein's ladder of participation [77]. 


\subsection{A Conceptual Framework for Urban Commons in Residential Landscapes}

This paper defines commons as a shared resource, collectively governed by a community of end users that maintain a bottom-up and inclusive approach to participation. A review of urban commons literature reveals several spatial, social and institutional implications of applying commons theory within the urban context. These include 1) understanding the spatial implications of sharing resources within the city, 2) the enablers of collective governance between strangers in the city, 3) the impact of collective governance on the creation of place and 4) the need for community groups to work within institutional urban frameworks. A preliminary conceptual framework for applying commons theory within an urban residential context (see Figure 3) draws upon various spatial theories in addressing some of these implications. In doing so, this paper outlines four preliminary concepts for applying commons theory to the urban context 1) the emergent common mindset in a complex-adaptive assemblage, 2) a spatial arrangement that reflects a shared territorial perception of 'ours', 3) opportunities for adaption and occupation of space as placemaking and 4) the reorientation of professional roles in delivering urban commons.

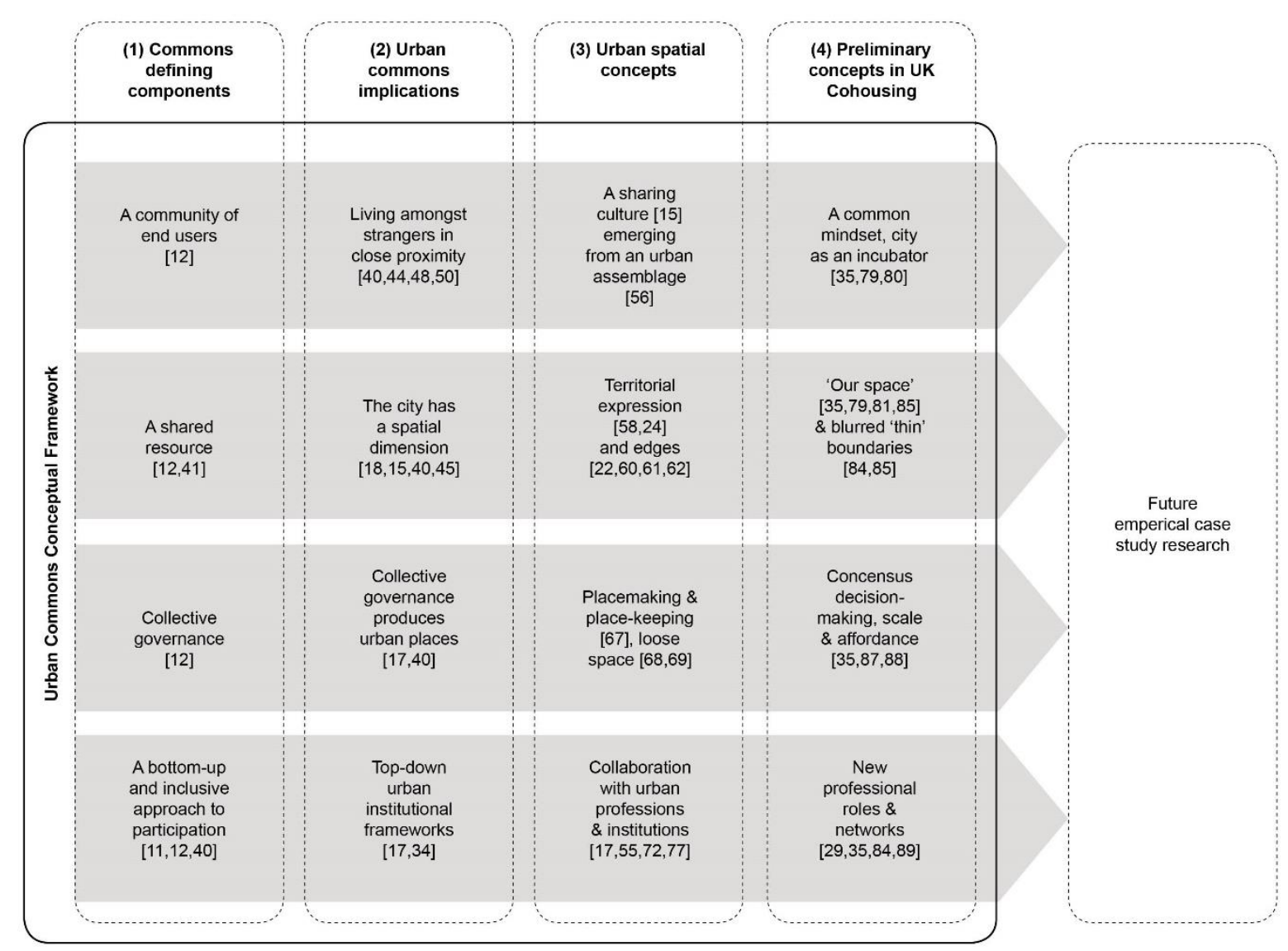

Figure 3. The urban commons framework consists of (1) the defining components of a commons, (2) the implications for these components in the urban context, (3) the relevant spatial concepts and theory in addressing the urban implications and (4) the key spatial ideas for the application of the urban commons in residential landscapes

\section{The Community-Led Housing Context}

The conceptual framework developed draws together multiple theories in addressing the urban implications of commons situated within the city. The purpose of this current section is to illustrate how this may be achieved in the residential landscape context and reinforce the preliminary framework developed through examples of recent research. The growing sector of community-led housing in the 
UK is drawn upon as an example of urban commoning in residential landscapes because it exemplifies high levels of resident participation in the instigation and governance of the site [31,39]. Specifically, this paper looks pre-emptively towards cohousing, a small but growing example of community-led housing, as an example of urban commons within the residential context. This section reviews recent UK cohousing literature to identify examples of how the urban commons framework could manifest within the residential landscape context.

\subsection{Cohousing and Its Emergence from a Common Mindset}

To understand the common mindset concept within the context of UK cohousing, this section first refers to the wider cohousing movement. It is important to understand the broad drivers for cohousing's emergence through a series of similar but contextually responsive ideological movements across the world. According to Meltzer [78], the first wave of cohousing began in Northern Europe (Denmark, Sweden and the Netherlands) in the 1960s and 1970s, propelled by two central beliefs: a communitarian desire to increase a sense of community and a feminist ideology to lighten the load of housework on women and improve the lifestyles of working parents. Transferred across to the USA in the 1980s and 1990s, the borrowed cohousing concept was driven by a striving for stronger social connections and an awareness of the need to build resilient neighbourhoods. This second wave of cohousing saw a number of developments adopting a significant environmental focus and utilising new sustainable building technologies. Cohousing did not begin to emerge in the UK until the late 1990s and has taken longer to establish itself than in other countries [34]. However, a recent revival of cohousing in the UK has seen a broader uptake of the idea. This most recent wave, whilst sharing some of the earlier social and environmental ideologies of cohousing seen in Europe and the US, also highlights a pragmatic economical response to unaffordability and the UK housing market. The overview of cohousing's global emergence suggests that the drivers and ideologies on which cohousing are founded have gone through various iterations, evolving to suit local contexts.

One such case from the literature review that demonstrates a collective response to these varied drivers, in the form of a common mindset, is LILAC cohousing in Leeds, UK. A recent paper [35] describes how LILAC was founded from initial discussions, covering a variety of individual views and expectations that were subsequently concentrated into a single vision for the project. The vision was based upon three core values: low-impact living, affordability and community. Chatterton [35] explains, "This led to the creation of the acronym 'Lilac' which summed up the social, economic and ecological ambitions of the project" (p. 1658). This quote suggests that LILAC emerged from similar responses to the global driving forces of previous waves of cohousing, but with a distinct socio-economic focus, endeavouring to ensure that housing remained affordable in the future. Chatterton describes the group's response to housing affordability in the UK as "the need to challenge an unsustainable housing model and develop an alternative based on economic equality among residents, permanent affordability, demarketization, nonspeculation and mutual co-ownership." [35] (p. 1662). LILAC, alongside broader observations of global cohousing movements, emerged from an underlying commonality, a collective desire to work together in response to both global and context-specific social, ecological or economical drivers. The common mindset not only appears to drive forward the project but also functions to attract new residents with similar values; "its name and values are directive enough to attract residents with a strong commitment to social and environmental justice" [35] (p. 1665). This quote from the paper describing the lessons learnt from LILAC, reinforces the idea that a shared ethos can help to invite like-minded residents to maintain a common mindset.

Sargisson describes such groups as intentional communities or "groups of people who have chosen to live (and sometimes work) together for some common purpose. Their raison d'être goes beyond tradition, personal relationships or family ties. They are places where people try to live their dreams on a daily basis" [79] (p. 34). Intentional communities begin with an initial forming phase [80,81], where a common purpose or common mindset is first outlined. The outlining of common values and goals within LILAC during the initial stages reinforces the idea that the foundations for a common mindset are made during the 
forming phase of the project. The value of the urban context in providing a significant resource pool for connecting together the necessary people and resources within the same common mindset is also mentioned in the paper: "Leeds offered a critical mass and a fortunate series of encounters, opportunities and informal networks to bring together active individuals and groups to kick start the idea" [35] (p. 1659). This highlights a distinct characteristic of the urban context in providing a 'critical mass' and coming together of individuals previously unknown to each other around a shared mindset.

The case of UK cohousing suggests that the common mindset is not a static element, but something that evolves through the phases of cohousing development and occupation. Establishing a common goal at the initial forming phase can play an additional role in creating social bonding, focusing group values and goals [80], reducing community conflicts and enabling harmonious decision making [82]. Research on UK and US cohousing case studies by Ruiu suggests that a common mindset is cultivated among residents' during their collective participation in the design process, also known as the storming phase. "... residents of communities involved in the research strongly believe that their participation in the designing process promoted more intimate relationships among members and increased their social capital in comparison with their previous situation. This led cohousers to know each other and solve conflicts that arose during the process due to their diverse points of view and needs ... spending a long period of time working together contributed to creating their community in both material and immaterial terms" [80] (p. 405). The evolution of the common mindset continues during the performing phase where shared goals are reinforced, renegotiated and adapted through the self-managed governance of the project. Within LILAC, the evolving shared agreements within the community are recorded by "... a number of community agreements ... devised to provide guidelines for members' individual behaviors, their interactions with others, and the use and management of shared spaces." [35] (p. 1661). Ongoing decision-making processes within cohousing ensure that decisions are made collectively and demonstrate how a common mindset might be preserved and adapted over time.

\subsection{The territorial Arrangement of Cohousing Centred on a Sense of Ours}

Cohousing characteristically combines both private individual dwellings and shared spaces [83], producing an intentional matrix of private, shared and public territories that allow an expression of both ours and mine. This makes cohousing an interesting case to explore the territorial arrangement of shared residential landscapes as urban commons and the resulting spatial boundaries between the individual, shared and wider public. Although each cohousing development has its own unique layout to suit the characteristics of the site and resulting from the community's input into the design process, cohousing developments share some distinctive spatial features. Many cohousing developments follow key design principles developed by US architects McCammant, Durrett and Hertzman [83] and are based on three typical layouts: linear street developments, clusters of houses around a central space or courtyard, or single buildings with internalised shared spaces [83]. Common to all of these layouts is the central positioning of shared spaces, inward-facing buildings and car parking at the peripheries, as illustrated in Figure 4. These spatial arrangements are based on principles that increase the use of shared spaces and encourage social interaction [6]. Devlin et al. [84], described this in an older women's cohousing where the "positioning of the entrance hall and common room as the focal point of the whole site and of arranging circulation routes so that paths cross and people are drawn together was fundamental" (p. 191). This results in a proximity of spaces perceived as 'mine' and 'ours' (Figure 4, (1)), and centralised car-free landscapes that increase the likelihood of social interaction (Figure 4, (2)). To further encourage the utilisation of shared spaces and social interaction, private space (and a sense of 'mine') is reduced [83]. In cohousing landscapes, this is achieved by reducing the size of private gardens in favor of shared space (Figures 2 and 4 (3) and (2)). Some communities found that negating all private space in favor of shared was not desirable, as in the case of the older women's cohousing in a study by Devlin et al. "But we are all individuals and it was equally important that each separate flat was as private and self sufficient at possible, with its very own little bit of outside space if at all possible." [84] (p. 191). 
As such, small areas that act as private space are positioned between private dwellings and shared open spaces as a buffer (Figure 4, (1) \& (4)).

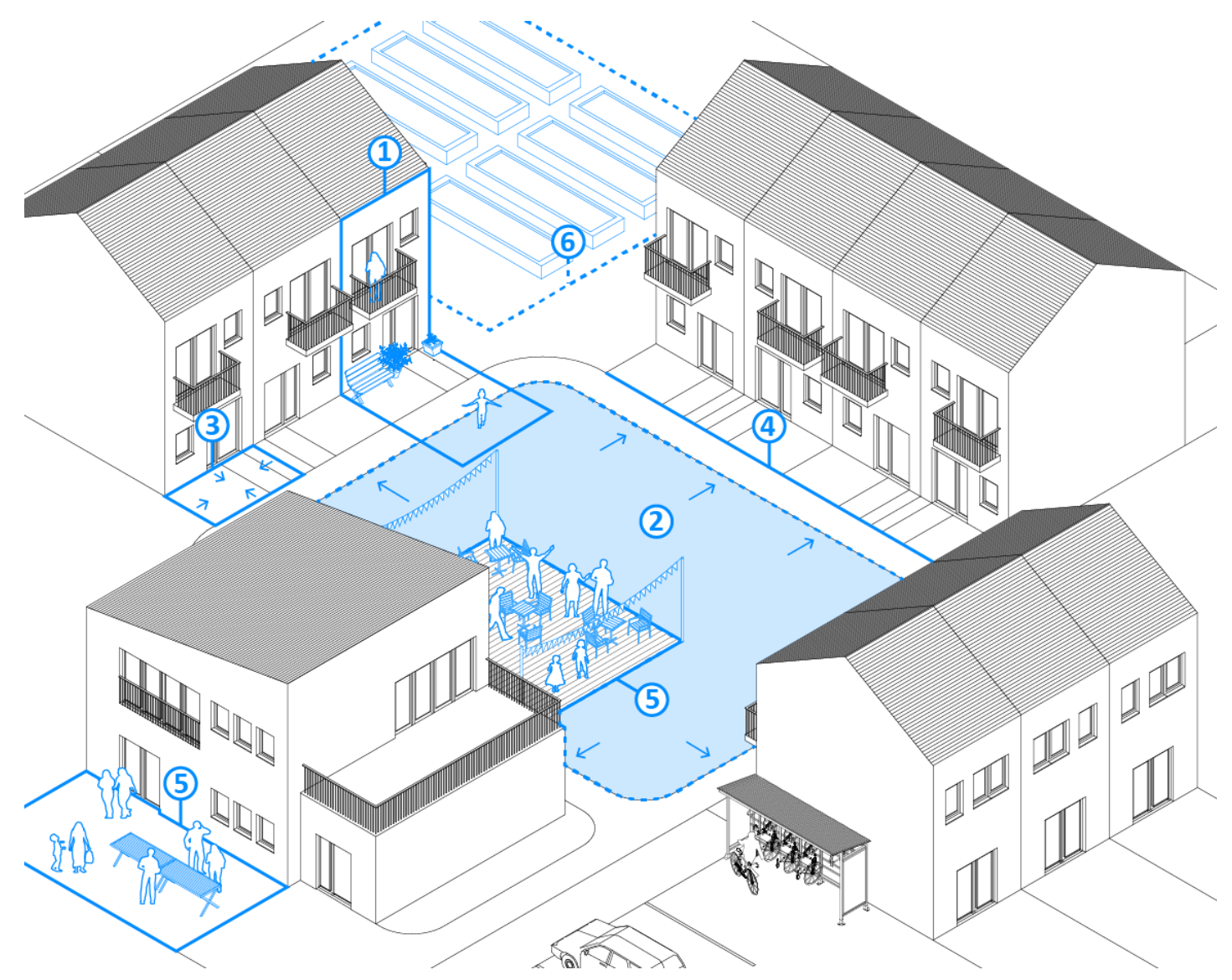

Figure 4. A diagram of a typical 'cluster' cohousing development illustrating the key spatial principles of residential urban commons: (1) proximity of 'mine' and 'ours'; (2) central shared landscape as our space; (3) reduction in private space; (4) thin boundaries between 'mine' and 'ours' (no hedges or fences); (5) flexible shared spaces that afford public events; (6) loose space left for community self-finish.

The central positioning of shared communal space surrounded by private dwellings, typical of most cohousing developments, creates distinct private-communal gradients, similar to, yet distinct from, the public-private gradients within most conventional housing developments (Figure 4, (1)). Ruiu [85] and McCammant et al. [83] observed that the boundaries between the private and communal spaces in cohousing are uniquely thin or soft in comparison to conventional public-private residential gradients (Figure 4, (4)). Higher levels of social interaction, participation in community life, trust and familiarity between residents allow the definition between cohousing residents' private spaces and communal spaces to become more ambiguous. In cohousing, the social blurring between communal and private is reinforced spatially by community agreements that ensure that members keep their front gardens unfenced or free of hedges and gates.

Several authors have highlighted that the cohousing arrangement produces a new kind of territorial realm that is public to residents yet private to outsiders $[79,81,85]$. The communal spaces within cohousing developments produce a territorial realm that simultaneously represents an 'ours' to cohousing resident and a 'theirs' to those in the wider neighbourhood. Some cohousing groups, attempt to mitigate this feeling of 'theirs' by making facilities available to the local community, running community events and holding open days [35]. This suggests that communal space within cohousing has the ability to become temporarily public through a kind of territorial slippage [69] (Figure 4, (5)) 
and that the boundaries between 'ours' and 'theirs', shared and public, have a certain permeability. A number of authors reinforced the need for further understanding of the territorial and spatial understanding at the collective scale [81] and its relation to the wider urban public scale [31,86]. Further empirical research on cohousing could provide insight into the spatial and temporal definition of 'ours' and how it can become spatially integrated within surrounding urban neighbourhoods.

\subsection{Cohousing Governance as Placemaking and Placekeeping}

Cohousing demands high levels of resident participation in the development stages, everyday decision-making and long-term governance of the place in which they live [31,32,39]. In this sense, cohousing residents can be understood to be taking part in a process of placemaking and placekeeping. As well as resident involvement in the design process at the forming phase of cohousing development [80], residents continually adapt and create place through their involvement in its long-term governance. Longer-term aspects of everyday governance are achieved in cohousing through the adoption of specific resident roles within the group, contributions during community workdays and shared meals, group meetings and decision-making processes [35]. Many cohousing groups utilise consensus decision making to formalise the collective governance process, a process by which a potential decision is put forward to a group of people, discussed and then adapted to address individual concerns, until full consensus is reached. As a result of the collective decision-making process, the LILAC paper [35] mentions the production of various community agreements that outline the "expectations and limits on different aspects of community life" (p. 1665). "Members are free to propose a community agreement and it is put forward as a proposal for discussion, amendment and then ratification. These cover areas such ... management of green spaces ... " [35] (p. 1665). In this example, written community agreements demonstrate a more formal approach to addressing decision making around placemaking and placekeeping. While consensus decision making ensures that individual concerns are addressed, gaining consensus within large groups can be time consuming. "For example, the initial centralised 'Development Group' worked well in the initial years but as the Society grew it could not manage with increased workloads." [35] (p. 1665). To address this issue, LILAC developed "Eight self-directed and participatory task teams [to] undertake routine decisions based on a preset remit in areas such as membership, landscaping, finance, maintenance, publicity, process, community outreach and learning/research." [35] (p. 1665). This example stresses the challenge of scaling up decision-making, which is well documented within urban commons literature $[11,12,40,87,88]$. Similar to Ostrom's theory of nested decision-making within larger scale and institutional commons [87], LILAC demonstrate an approach to the challenge of scale by creating tiered and informal decision making for routine aspects of the project within working groups.

Building in opportunities for placemaking in the residential landscape is an important role of the design profession in cohousing and urban residential landscapes more broadly. One approach in enabling high levels of resident participation in placemaking in cohousing is by incorporating looseness through a self-build or a partial self-finish approach. A self-build approach, where residents take the role of contractors and take on responsibility for the full build, often requires too large a time and resource commitment and high levels of skills and expertise for most residents. Self-finish provides a potential option for those residents by leaving aspects of the development purposively unfinished in agreement with residents to allow participation in the making of their own homes and surroundings. Self-finish is a phrase that usually refers to the provision of an unfinished but structurally integral shell of a house for residents, but could also include leaving the building and planting of landscapes unfinished (Figure 4. (6)). Fishponds road cohousing in Bristol is one such cohousing example that took on a self-finish approach. In a published interview with one of the development's residents [89], the collective self-finish process is described as having social benefits, but also challenges surrounding the balancing of expectations, time, input and guidance. Residents of Fishponds road cohousing addressed some of these issues with 'sweat equity', a term used to measure individual contributions, in the form of building equity or reduced rent, in return for the hours spent in finishing the project. 
The above example demonstrates one way in which a balance between community autonomy and professional input can be achieved, however, further understanding is required to address the challenges faced in this area. Hammond [90] begins to address this lack of understanding by exploring ways in which flexibility can be incorporated in his collaborative 'spatial agency' approach to design with an older people's cohousing group in Manchester. He discusses how flexibility in the design of spaces to afford changing uses over time were important to the group he worked with. "Rather than pre-determining the functions of these spaces, they felt it more important to create spaces with different spatial characteristics that they could appropriate for different uses as they emerged. This position was in recognition that the group's needs would inevitably change as they grew older, but that the types of shared activities the group might want to undertake in the future are unknown to them at present." [90] (p. 10). Hammond emphasises a need for an understanding of cohousing groups' desire to be involved in landscape management and maintenance from the outset, so that a more collaborative role can be adopted by design professionals and community ideas can be incorporated into the overall design.

\subsection{Cohousing, Partnerships with Professionals and Working within Institutions}

UK cohousing groups, in comparison to other European countries, have been slow in establishing themselves due to a tendency for new groups to reinvent the wheel [34] and the challenges presented in negotiating top-down frameworks. This is something that Chatterton [35] highlights in LILAC's experience of implementing their social, economic and ecological goals: "To deliver its objectives simultaneously requires working across a set of complex institutional and governance frameworks and scales, including legal, financial, planning, ecological, community liaison, design and governance issues. The ability to do this is extremely difficult as it challenges conventional wisdom in terms of the functioning of housing markets, land ownership, building fabric choices and community self-governance, which is reinforced by the silos and specialisms that most professions, especially central government departments and large volume housing builders, operate within. The challenge is to strategically build governance frameworks that promote holistic approaches" (p. 1667). A review of cohousing literature reinforces this call for more widely adopted planning, financial and institutional infrastructures to support cohousing and collaborations between local councils, social and private developers, lenders and cohousing groups [34].

With the rise in popularity surrounding cohousing in recent years, the establishment of several pioneering cohousing examples in the UK, and the community-led housing fund, a collaboration between cohousing communities and outside professionals is emerging to enable groups to overcome these barriers. This has led to the specialisation of some professions in dealing with cohousing groups using participatory approaches to cohousing design and development. For example, the recently completed Marmalade Lane cohousing [91] was built on a collaboration between the local council, a custom-build housing developer, a Swedish sustainable development consultant, architects, and the $\mathrm{K} 1$ cohousing group. The emphasis on collaboration, rather than a traditional client-profession relationship, highlights a need for equal input and partnership between the cohousing community and professions, in an attempt to balance power relations. This new facilitating role and emphasis on collaboration and partnership rather than traditionally professional procurement is explored in Hammond's reflection on his facilitating role with the older people's cohousing group in Manchester. He highlights, that whilst cohousing groups are actively involved in creating a collective identity and ethos, they "are disempowered from exploring the spatial implications and possibilities of these ideas" [90] (p. 4). Hammond investigates a method for overcoming this disempowerment by developing a new architect-cohouser relationship that enables the social identity of the cohousing group to develop alongside the spatial design development. He emphasises that the design professional be involved at the earliest opportunity and for them to adopt a facilitating and interpretive role.

Working with professionals presents a number of benefits to cohousing groups. For example, Devlin, Douglas and Reynolds [84] highlight the important role professionals have in communicating and negotiating the community's vision within planning frameworks. In addition, partnerships with external organisations and institutions may provide opportunities for broader inclusion of people 
from a range of backgrounds [85]. Despite these benefits, Ruiu [80] highlights that engagement with top-down processes within cohousing may result in a loss of community control and an erosion of the common mindset that it is built upon. The challenge within cohousing, as in other types of urban commons, is maintaining a pathway for bottom-up communication, a sense of collective control and identity, while at the same time collaborating with external organisations to negotiate urban frameworks. Part of the answer to this challenge may lie in the development of intermediary networks and organisations working on a national scale to support communities, such as the UK Cohousing Network and Community Led Homes organisation [33,92]. LILAC worked with a number of outside professions and networks in order to break these barriers. These included "the local Green Party who brokered a meeting with the leader of the Council, grassroots organizations such as the Permaculture Network, the Co-operative Development Agency, and Sustainable Futures Leeds who provided early support, as well as founder members who had built up experience in housing cooperatives and community organizing in the city" [35] (p. 1659). This suggests that intermediary networks and existing contacts from cohousing members play an important role in negotiating the barriers created by institutional frameworks and the groups' ability to maintain community control.

\subsection{Summary of Provisional Findings}

Up to now, chapter 5 discusses examples found within UK cohousing literature to illustrate the key concepts outlined in the conceptual framework for urban commoning in shared residential landscapes, derived from a literature review. This illustration reinforces the four key concepts within the framework and elaborates upon them to suggest a number of preliminary findings and areas of interest for future research. The UK cohousing literature provides an illustration of the conceptual framework for residential landscape urban commons in a number of ways:

A common mindset and the city as an incubator: Through the initial group discussions that collectively outlined the group's values and goals and cemented them within the project name acronym, LILAC highlights the group's formation from a common mindset. The process of developing shared values and goals establishes a common mindset that enables a diversity of people within the urban context to work together in pursuit of a common goal. This idea is echoed by Huron [50] and Sargisson [79] and helps to explain how urban commons establish the community of end users component within the context of the city that consists of relatively diverse and transient populations. In addition, the LILAC example suggests that the common mindset acts as a magnet to attract residents who share the same values. Chatterton's description of the city providing "a fortunate series of encounters, opportunities and informal networks" (p. 1659) suggesting that the city itself acts as an incubator for the common mindset by providing a critical mass of like-minded individuals and potential for dynamic connections and networks. This is reinforced by Dovey's understanding of the city as a dynamic and networked urban assemblage [56].

Our space and thin boundaries: The cohousing literature discussed outlines a number of spatial and territorial ideas around the concept of our space that is central to the common mindset concept. This provides new spatial insight into urban commons as residential landscapes, which is illustrated in Figure 4. Firstly, typical cohousing layouts emphasise spatial arrangements that encourage social interaction, such as a proximity of 'mine' and 'ours' (Figure 4, (1)), central shared landscapes (Figure 4, (2)), a reduction in private space (Figure 4, (3)) and internalised pedestrian circulation routes. This emphasises that spatial layouts that encourage both social and spatial interaction in shared spaces are important for residential urban commons. Secondly, investigation of cohousing research suggests a blurring of territorial clarity between private and shared in cohousing landscapes $[83,85]$. These boundaries have been described as being particularly thin, something that is both socially and spatially reinforced in some cohousing agreements (Figure 4, (4)). Finally, the research on cohousing highlights a tension between public and shared spaces, which parallels the tensions between open and enclosure within urban commons literature. The cohousing examples suggest a temporal fluidity in shared-public boundaries enable residents' flexibility to briefly open up shared spaces to the 
wider public, while retaining a sense of community privacy and shared ownership (Figure 4, (5)). These findings are supported by urban spatial theory $[22,58,60]$ that suggests a need for soft transitional edges between territorial boundaries.

Scales of decision-making and affordance: UK cohousing use processes of consensus-decision making, tiered organisation and participatory design processes to enable placemaking and placekeeping in governing urban commons. Larger groups and time required can be barriers to collectively achieving the decision-making required in placemaking. Initial examples suggest smaller working groups and a combination of formal and informal agreements may be required to tackle these challenges. In addition, new ways of building in looseness into the design, such as self-finish approaches, could enable residents to have greater participation in the landscape and balance the need for professional design input and guidance (Figure 4, (6)).

New professional roles and networks: The UK cohousing illustration suggests institutional frameworks and top-down processes remain difficult for urban commons groups to negotiate. Intermediary organisations and networks, horizontal knowledge sharing and design professionals play an important role in negotiating those frameworks and processes. Within the urban context, where institutional frameworks are more prominent, collaborating with professionals may be more important than in traditional rural commons. The LILAC example also demonstrates the necessary support that intermediary networks and existing contacts provide in negotiating urban institutional frameworks. This calls for a new role from urban professionals to facilitate the negotiation. Hammond [90], in particular, suggested that professionals need to be involved at an earlier stage in the process during the development of the common mindset.

\section{Conclusions}

This paper presents a new conceptual framework that situates urban commons inside the broader discourse of sustainable residential landscapes. This deepens the spatial understanding of urban commons and creates a foundation for further research. To clarify commons terminology, this paper investigates the reinterpretations of the commons concept to provide a single overarching definition comprising of the relationship between four essential components: a community of end users, a shared resource, collective governance and inclusive participation. In doing so, this review also demonstrates the limitations of commons theory in understanding the new urban context in which it is emerging, in particular, a need for an urban and spatial understanding for implementing the idea in shared residential landscapes. This need is addressed by looking toward existing urban spatial theory and examples of UK cohousing research to situate the concepts within the urban residential context.

The findings of this review highlight the potential of the urban context in providing a critical mass of like-minded people and a dynamic potential for networks and connections to drive forward projects involved in collectively managing shared residential landscapes. A number of spatial concepts common in urban spatial theory, such as our space, thin territorial boundaries, loose space and temporality, are connected to residential urban commons to provide new spatial insight into the emerging idea. Finally, this paper also highlights the tensions between bottom-up processes of placemaking and placekeeping with the need for professional collaboration in negotiating the complex institutional frameworks within cities. In observing the emerging practices and limitations highlighted within the UK cohousing literature, it is suggested that a new collaborative role for urban professions is required to facilitate the converging of top-down and bottom-up processes, alongside new intermediary organisations and networks.

The implications of these findings are relevant for residential urban commons groups (cohousing communities specifically), potential external partners, such as planners and urban designers, and researchers. For urban commons groups, this conceptual framework provides an awareness of the common mindset and its purpose, utilising the connections and networks afforded by the city, and the importance of working collaboratively with external organisations. For external partners, this paper highlights a new facilitating role required to carve out new types of relationships with 
urban commoning groups that preserves their collective identity and ability to self-govern. It also highlights a number of spatial concepts specific to residential urban commons and cohousing that design professionals should be aware of.

The framework itself (Figure 3) lays out the groundwork in joining previously disconnected theories related to urban commons in residential landscapes and guides new lines of inquiry into the spatial dimension of urban commons (Figure 4). The lack of empirical research on this topic to draw on highlights the preliminary nature of the findings developed from a solely review-based approach. By emphasising the lack of spatial understanding within urban commons theory, this paper lays foundations for further empirical investigation surrounding commoning within the urban residential context building from the conceptual framework developed. In particular, the conceptual framework offers a foundation for more comprehensive case-study-focused research that can highlight specific empirical responses to the urban implications highlighted in this paper. For researchers, these preliminary findings open up new lines of inquiry relating to urban commons in residential landscapes. This may include longitudinal research on the establishment, development and potential fragmenting of the common mindset, more detailed empirical evidence of the spatial concepts outlined in this paper, and how these spatial concepts and new top-down roles can be implemented in design practice and in a wider variety of residential contexts. Finally, the broader potential and application of the conceptual framework should be explored. In particular, urban commons have previously been linked as a potential component in building resilient cities [93-95] and therefore, the framework has potential for application to wider urban challenges.

Author Contributions: Conceptualisation, A.F., K.T. and J.S.; writing-original draft preparation, A.F.; writing-review and editing, A.F., K.T. and J.S.; supervision, K.T..; funding acquisition, A.F.

Funding: This work was supported by the Economic and Social Research Council [ES/P000746/1].

Conflicts of Interest: The authors declare no conflict of interest.

\section{References}

1. Amin, A.M. Sustainable urban landscape: An approach for assessing and appropriating indicators. Int. J. Archit. Res. 2012, 6, 98-114.

2. Burley, J.; Deyoung, G.; Partin, S.; Rokos, J. Reinventing Detroit: Reclaiming Grayfields-New Metrics in Evaluating Urban Environments. Challenges 2011, 2, 45-54. [CrossRef]

3. Gehl, J. Cities for People; Island Press: Washington, DC, USA, 2010.

4. Urban Sustainability Through Environmental Design: Approaches to Time-People-Place Responsive Urban Spaces; Thwaites, K.; Porta, S.; Romice, O.; Greaves, M. (Eds.) Taylor \& Francis Ltd.: London, UK, 2007.

5. Smith, C.; Clayden, A.; Dunnett, N. Residential Landscape Sustainability: A Checklist Tool; Blackwell Publishing Ltd.: Chichester, UK, 2007.

6. Williams, J. Designing neighbourhoods for social interaction: The case of cohousing. J. Urban Des. 2005, 10, 195-227. [CrossRef]

7. Nonini, D. Theorizing the urban housing commons. Focaal 2017, 2017, 23-38. [CrossRef]

8. Iaione, C. The CO-City: Sharing, Collaborating, Cooperating, and Commoning in the City. Am. J. Econ. Sociol. 2016, 75, 414-455. [CrossRef]

9. Susser, I.; Tonnelat, S. Transformative cities: The three urban commons. Focaal 2013, 2013, 105-122. [CrossRef]

10. Gidwanii, V.; Baviskar, A. Urban Commons. Econ. Politcal Wkly. 2011, 46, 42-43.

11. Helfrich, S.; Bollier, D. Free, Fair and Alive: The Insurgent Power of the Commons; New Society Publishers: Gabriola Island, BC, Canada, 2019.

12. Ostrom, E. Governing the Commons: The Evolution of Institutions for Collective Action; Cambridge University Press: Cambridge, UK, 1990.

13. Hess, C. Mapping the New Commons. In Proceedings of the The Twelfth Biennial Conference of the International Association for the Study of the Commons, Cheltenham, UK, 14-18 July 2008. 
14. Bollier, D. The growth of the commons paradigm. In Understanding Knowledge as a Commons; Hess, C., Ostrom, E., Eds.; MIT Press: Cambridge CA, USA, 2007; pp. 27-40.

15. Katrini, E. Sharing Culture: On definitions, values, and emergence. Sociol. Rev. 2018, 66, 425-446. [CrossRef]

16. Harvey, D. The Right to the City. New Left Rev. 2008, 53, 23-40.

17. Foster, S.; Iaione, C. The City as a Commons. Yale Law Policy Rev. 2016, 281-349. [CrossRef]

18. Moss, T. Spatiality of the commons. Int. J. Commons 2014, 8, 457-471. [CrossRef]

19. HM Treasury. Autumn Budget 2017; HMSO: London, UK, 2017.

20. Cooper Marcus, C.; Sarkissian, W. Housing As If People Mattered: Site Design Guidelines for the Planning of Medium-Density Family Housing (california Series In Urban Development), 1st ed.; University of California Press: Berkeley, CA, USA, 1988.

21. Hye, H.Y.; Chan, J.; Guizzo, A.O.; Yok, T.P. Neighbourhood Landscapes. In Nature, Place and People: Forging Connections through Neighbourhood Landscape Design; Yok, T.P., Liao, K.H., Hye, H.Y., Chua, V., Eds.; World Scientific Publishing Co. Pte. Ltd.: Singapore, 2018; pp. $24-57$.

22. Gehl, J. Life Between Buildings: Using Public Space; The Danish Architectural Press: Copenhagen, Denmark, 2006.

23. Thwaites, K.; Helleur, E.; Simkins, I.M. Restorative urban open space: Exploring the spatial configuration of human emotional fulfilment in urban open space. Landsc. Res. 2005, 30, 525-547. [CrossRef]

24. Thwaites, K. Expressivist Landscape Architecture: The Development of A New Conceptual Framework for Landscape Arhictecture. Landsc. J. 2000, 19, 201-210. [CrossRef]

25. Fox-Kämper, R.; Wesener, A.; Münderlein, D.; Sondermann, M.; McWilliam, W.; Kirk, N. Urban community gardens: An evaluation of governance approaches and related enablers and barriers at different development stages. Landsc. Urban Plan. 2018, 170, 59-68. [CrossRef]

26. Aernouts, N.; Ryckewaert, M. Beyond housing: On the role of commoning in the establishment of a Community Land Trust project. Int. J. Hous. Policy 2018, 18, 503-521. [CrossRef]

27. Felbinger, D.; Jonuschat, H. Promoting neighbourly interactions by the common use of green spaces. In Proceedings of the ENHR conference Housing in an expanding Europe: Theory, Policy, Participation and Implementation, Ljubljana, Slovenia, 2-5 July 2006; pp. 1-16.

28. Arrigoitia, M.F.; Tummers, L. Cohousing Professionals as Middle-Agents: Perspectives from the UK, USA and the Netherlands. Built Environ. 2019, 45, 346-363. [CrossRef]

29. Ruiu, M.L. Participatory processes in designing cohousing communities: The case of the community project. Hous. Soc. 2016, 43, 168-181. [CrossRef]

30. GOV.UK Homes England; Community Housing Fund. 2018. Available online: https://www.gov. uk/government/collections/community-housing-fund\#community-housing-fund-prospectus (accessed on 10 November 2018).

31. Fromm, D. Seeding Community: Collaborative Housing as a Strategy for Social and Neighbourhood Repair. Built Environ. 2012, 38, 364-394. [CrossRef]

32. Durrett, C. The Senior Cohousing Handbook: A Community Approach to Independent Living, 2nd ed.; New Society Publishers: Gabriola Island, BC, Canada, 2009.

33. UK Cohousing Network. UK Cohousing Directory. Available online: https://cohousing.org.uk/information/ uk-cohousing-directory/ (accessed on 1 May 2019).

34. Jarvis, H.; Scanlon, K.; Fernández Arrigoitia, M.; Chatterton, P.; Kear, A.; O’Reilly, D.; Sargisson, L.; Stevenson, F. Cohousing: Shared Futures. 2016. Cohousing Network website. Available online: https://cohousing.org.uk/wp-content/uploads/2017/03/Cohousing-shared-futures-2016.pdf (accessed on 4 July 2019).

35. Chatterton, P. Towards an agenda for post-carbon cities: Lessons from lilac, the uk's first ecological, affordable cohousing community. Int. J. Urban Reg. Res. 2013, 37, 1654-1674. [CrossRef]

36. Durrett, C.; McCamant, K. Creating Cohousing; New Society Publisher: Gabriola Island, BC, Canada, 2011.

37. Meltzer, G. Sustainable Community: Learning From the Cohousing Model, 3rd ed.; Trafford Publishing Ltd.: Crewe, UK, 2005.

38. Brenton, M. We're in Charge: Cohousing Communities ofOlder People in the Netherlands_Lessons for Britain? Policy Press: Bristol, UK, 1998. 
39. Czischke, D. Collaborative housing and housing providers: Towards an analytical framework of multi-stakeholder collaboration in housing co-production. Int. J. Hous. Policy 2018, 18, 55-81. [CrossRef]

40. Harvey, D. Rebel cities: From the Right to the City to the Right to the Urban Revolution; Verso: London, UK, 2012.

41. Hardin, G. The tragedy of the commons. Science 1968, 162, 1243-1248. [PubMed]

42. Hess, C.; Ostrom, E. Introduction: An Overview of the Knowledge Commons. In Understanding Knowledge as a Commons: From Theory To Practice; Hess, C., Ostrom, E., Eds.; MIT Press: Cambridge, MA, USA, 2011; pp. 3-26.

43. Kollock, P.; Smith, M. Managing the Virtual Commons: Cooperation and Conflict in Computer Communities. In Computer-Mediated Communication: Linguistic, Social, and Cross-Cultural Perspectives; Herring, S., Ed.; John Betjamins: Amsterdam, The Netherlands, 1996.

44. Parker, P.; Schmidt, S. Enabling urban commons. CoDesign 2017, 13, 202-213. [CrossRef]

45. Lefebvre, H. Writing on Cities; Kofman, E., Lebas, E., Eds.; Blackwell Publishers: Cambridge, MA, USA, 1996.

46. Berleant, A. Living in the Landscape: Toward an Aesthetics of Environment; University Press of Kansas: Kansas, KS, USA, 1997.

47. Alexander, C.; Ishikawa, S.; Silverstein, M.; Jacobson, M.; Fiksdahl-King, I.; Angel, S. A Pattern Language, 38th ed.; Oxford University Press: New York, NY, USA, 1977.

48. Bingham-Hall, J. Future of Cities: Commoning and Collective Approaches To Urban Space; Government Office for Science: London, UK, 2016.

49. Huron, A. Theorising the urban commons: New thoughts, tensions and paths forward. Urban Stud. 2017, 54, 1062-1069. [CrossRef]

50. Huron, A. Working with Strangers in Saturated Space: Reclaiming and Maintaining the Urban Commons. Antipode 2015, 47, 963-979. [CrossRef]

51. Lofland, L.H. A World Of Strangers: Order and Action in Urban Public Space; Basic Books, Inc.: New York, NY, USA, 1973.

52. Bresnihan, P.; Byrne, M. Escape into the city: Everyday practices of commoning and the production of urban space in Dublin. Antipode 2015, 47, 36-54. [CrossRef]

53. Udall, J. Mending the commons with the Little Mesters. Ephemera 2019, 19, 253-281.

54. Thompson, M. Between Boundaries: From Commoning and Guerrilla Gardening to Community Land Trust Development in Liverpool. Antipode 2015, 47, 1021-1042. [CrossRef]

55. Dobson, J. From me towns to we towns: Activist citizenship in UK town centres. Citizensh. Stud. 2017, 21, 1015-1033. [CrossRef]

56. Dovey, K. Informal urbanism and complex adaptive assemblage. Int. Dev. Plan. Rev. 2012, 34, 349-368. [CrossRef]

57. Wirth, L. Urbanism as a Way of Life. Am. J. Sociol. 1938, 44, 1-24. [CrossRef]

58. Habraken, N.J. The Structure of the Ordinary: Form and Control in the Built Environment; MIT Press: London, UK, 1998.

59. Honneth, A. The Struggle for Recognition: The Moral Grammar of Social Conflicts; Polity Press: Cambridge, UK, 1995.

60. Thwaites, K.; Mathers, A.; Simkins, I. Socially Restorative Urbanism: The Theory, Process and Practice of Experiemics; Taylor \& Francis: Abingdon, UK, 2013.

61. Martin, M.D. The case for residential back-alleys: A North American perspective. J. Hous. Built Environ. 2002, 17, 145-171. [CrossRef]

62. Appleton, J. The Experience of Landscape; John Wiley \& Sons: London, UK, 1975.

63. Hall, E.T. The Hidden Dimension; Anchor Books: New York, NY, USA, 1969.

64. Dovey, K.; Wood, S. Public/private urban interfaces: Type, adaptation, assemblage. J. Urban. 2015, 8, 1-16. [CrossRef]

65. Newman, O. Defensible Space: Crime Prevention Through Urban Design. Am. Polit. Sci. Rev. 1973, 69, 264.

66. Project for Public Spaces What Is Placemaking? Available online: https://www.pps.org/article/what-isplacemaking (accessed on 23 April 2019).

67. Dempsey, N.; Burton, M. Defining place-keeping: The long-term management of public spaces. Urban For. Urban Green. 2012, 11, 11-20. [CrossRef] 
68. Franck, K.A.; Stevens, Q. Loose Space: Possibility and Diversity in Urban Life; Routledge Taylor \& Francis Group: Abingdon, UK, 2006.

69. Dovey, K. Becoming Places: Urbanism/Architecture/Identity/Power; Routledge: Oxon, UK, 2010.

70. Dempsey, N.; Smith, H.; Burton, M. (Eds.) Place-Keeping: Open Space Management in Practice; Routledge: Oxon, UK, 2014.

71. Madanipour, A.; Miciukiewicz, K.; Vigar, G. Master plans and urban change: The case of Sheffield city centre. J. Urban Des. 2018, 23, 465-481. [CrossRef]

72. Tonkiss, F. Austerity urbanism and the makeshift city. City 2013, 17, 312-324. [CrossRef]

73. Dennis, M.; James, P. User participation in urban green commons: Exploring the links between access, voluntarism, biodiversity and well being. Urban For. Urban Green. 2016, 15, 22-31. [CrossRef]

74. Allen, J.O.; Alaimo, K.; Elam, D.; Perry, E. Growing vegetables and values: Benefits of neighborhood-based community gardens for youth development and nutrition. J. Hunger Environ. Nutr. 2008, 3, 418-439. [CrossRef]

75. Communities in Control. CiC Research Summary 1: How Is Collective Control Developing Among Residents Involved in the Big Local Programme? 2015. Communities in Control website. Available online: https:/communitiesincontrol.uk/wp-content/uploads/2019/01/CiC-Summary-1-CollectiveControl-final.pdf (accessed on 4 July 2019).

76. Shared Assets. Transforming Derelict or Underused Land Through Community-Led Models: A Guide Inspired by the Experience of Our Place Projects. 2016. My Community, locality website. Available online: https://mycommunity. org.uk/wp-content/uploads/2016/09/10-Reclaiming-land-v-4-FINAL-1.pdf (accessed on 5 October 2018).

77. Arnstein, S.R. A Ladder of Citizen Participation. J. Am. Plan. Assoc. 1969, 35, 216-224. [CrossRef]

78. Meltzer, G. Co-housing bringing communalism to the world? In Proceedings of the 7th International Communal Studies Conference Association, Communal Living on the Threshold of a New Millennium: Lessons and Perspectives, Belzig, Germany, 25-27 June 2001.

79. Sargisson, L. Friends have all things in common: Utopian property relations. Br. J. Polit. Int. Relations 2010, 12, 22-36. [CrossRef]

80. Ruiu, M.L. The Social Capital of Cohousing Communities. Sociology 2016, 50, 400-415. [CrossRef]

81. Jarvis, H. Saving space, sharing time: Integrated infrastructures of daily life in cohousing. Environ. Plan. A 2011, 43, 560-577. [CrossRef]

82. Bouma, J.T.; Poelman, W.A.; Voorbij, A.I.M. Supporting social contact design principles in common areas of cohousing communities. Unpublished work. 2010. Available online: https://www.academia.edu/4722409/ Supporting_social_contact_design_principles_in_common_areas_of_cohousing_communities (accessed on 15 November 2018).

83. McCamant, K.; Durett, C.; Hertzman, E. Cohousing: A Contemporary Approach to Housing Ourselves, 2nd ed.; Habitat Press/Ten Speed Press: Berkeley, CA, USA, 1994.

84. Devlin, P.; Douglas, R.; Reynolds, T. Collaborative design of older women's co-housing. Work. Older People 2015, 19, 188-194. [CrossRef]

85. Ruiu, M.L. Differences between Cohousing and Gated Communities. A Literature Review. Sociol. Inq. 2014, 84, 316-335. [CrossRef]

86. Tummers, L. The re-emergence of self-managed co-housing in Europe: A critical review of co-housing research. Urban Stud. 2016, 53, 2023-2040. [CrossRef]

87. Ostrom, E. Nested externalities and polycentric institutions: Must we wait for global solutions to climate change before taking actions at other scales? Econ. Theory 2012, 49, 353-369. [CrossRef]

88. Giordano, M. The Geography ofthe Commons: The Role of Scale and Space. Ann. Assoc. Am. Geogr. 2003, 93, 365-375. [CrossRef]

89. Stride Treglown. Martin Horne: Self-Finish Living. Available online: https://stridetreglown.com/inhabitant/ martin-horne-self-finish-living/ (accessed on 23 September 2019).

90. Hammond, M. Spatial Agency: Creating New Opportunities for Sharing and Collaboration in Older People's Cohousing. Urban Sci. 2018, 2, 64. [CrossRef]

91. Trivselhus UK. Marmalade Lane. Available online: https://marmaladelane.co.uk/ (accessed on 10 July 2019).

92. Community Led Homes. Types of Community-led Housing. Available online: https://www. communityledhomes.org.uk/types-of-community-led-housing (accessed on 10 July 2019). 
93. Esopi, G. Urban commons: Social resilience experiences to increase the quality of urban system. TeMA J. Land Use 2018, 2, 173-194.

94. Baibarac, C.; Petrescu, D. Open-source Resilience: A Connected Commons-based Proposition for Urban Transformation. Procedia Eng. 2017, 198, 227-239. [CrossRef]

95. Colding, J.; Barthel, S.; Bendt, P.; Snep, R.; van der Knaap, W.; Ernstson, H. Urban green commons: Insights on urban common property systems. Glob. Environ. Chang. 2013, 23, 1039-1051. [CrossRef]

(C) 2019 by the authors. Licensee MDPI, Basel, Switzerland. This article is an open access article distributed under the terms and conditions of the Creative Commons Attribution (CC BY) license (http://creativecommons.org/licenses/by/4.0/). 